\title{
ERRATUM
}

\section{FLORAL $\mathrm{CO}_{2}$ REVEALS FLOWER PROFITABILITY TO MOTHS}

\section{CORINNA THOM, ${ }^{*}$ PABLO G. GUERENSTEIN, WENDY L. MECHABER, and JOHN G. HILDEBRAND}

Due to errors by the Publisher, Fig. 1 and the reference IPCC 2001 in the above paper (which was originally published in Vol. 30, No. 6, June 2004) were incorrectly represented. The correct representations appear below.

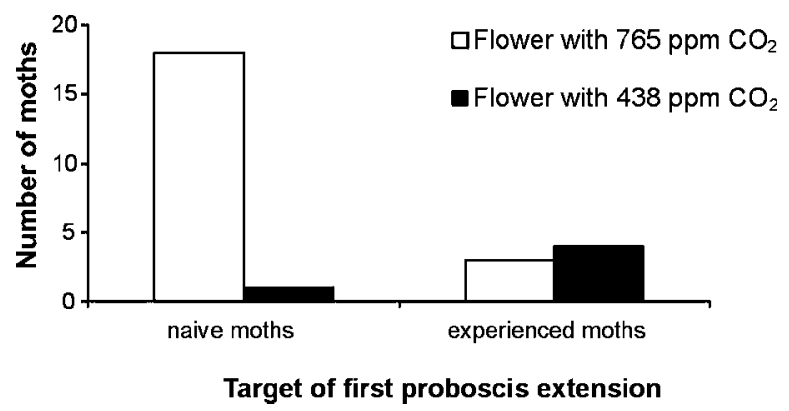

FIG. 1. Targets of the first proboscis extensions (feeding attempts) of naïve and experienced Manduca moths: number of moths targeting the surrogate flower with a high level of $\mathrm{CO}_{2}$ as typical for newly opened Datura flowers (765 ppm, white bars), and an approximately ambient level of $\mathrm{CO}_{2}$ (438 ppm, black bars). The position of flowers in the room did not affect the outcome of experiments. Only the first proboscis extension of a moth during each experiment was considered for analysis of foraging preference, as the first experience might affect successive foraging decisions.

Reference change:

IPCC. 2001. Climate Change 2001: The Scientific Basis (Report of Working Group 1 of the Intergovernmental Panel on Climate Change, IPCC Secretariat, Geneva, 2001).

* To whom correspondence should be addressed. E-mail: thom@neurobio.arizona.edu. 